\title{
University libraries provide intellectual property information service in China: theoretical framework and system development
}

\author{
Congjing Ran \\ School of Information Management, Wuhan University, \\ Wuhan, China, and \\ Kai Song and Le Yang \\ Wuhan University, Wuhan, China
}

\begin{abstract}
Purpose - There is no proposed solution to address the unresolved issues of constructing the Chinese university intellectual property information service system (IPISS) to promote the whole process service efficiency of IP creation, utilization, protection and management. The purpose of this paper is to propose a complete system, including theoretical framework and system development which addresses the existing difficulties to IP create, protect and transfer for researchers in universities. The paper shares the practice of utilizing the system developed by Wuhan University IP research team known as Wuhan University Intellectual Property Information Service System (WHU-IPISS).

Design/methodology/approach - First, the IPISS of 23 universities in China was investigated on the internet. Aiming at the deficiencies of the system, such as single service type, lack of patent display window, low management efficiency. This paper constructs the theoretical framework, proposes the IP ecological chain model, divides it into four sub-chains and carries on the functional design. Further, under the theoretical framework, the IPISS was developed, including the resource supply management system, user demand matching system, resource assessment system and expert support system. Finally, the system was applied to Wuhan University to provide IP services in the whole process for university researchers.

Findings - WHU-IPISS realizes the functions of IP resource supply, demand matching, value evaluation and expert support. It solves the IP needs of university researchers and provides a guarantee for their technology research, patent portfolio, patent transfer and patent rights protection. It also improves the efficiency of IP service and can construct the IP ecosphere in universities.

Originality/value - The WHU-IPISS solution resolves issues of "How to develop the university IP whole process service model, fulfilling the IP service needs for universities' researchers". The software will be released as open-source for other universities' use. The publishing model is also useful for those universities that intend to implement the IPISS.
\end{abstract}

Keywords Intellectual property services, University libraries, System development, Intellectual property information service platform, System software, Information system

Paper type Case study

(C) Congjing Ran, Kai Song and Le Yang. Published in Journal of Industry-University Collaboration. Published by Emerald Publishing Limited. This article is published under the Creative Commons Attribution (CCBY 4.0) licence. Anyone may reproduce, distribute, translate and create derivative works of this article (for both commercial and non-commercial purposes), subject to full attribution to the original publication and authors. The full terms of this licence may be seen at http://creativecommons. org/licences/by/4.0/legalcode.

The research is supported by the General Program of National Natural Science Foundation of China (Grant No. 71774123).

Constructing the Chinese university IPISS

Received 8 October 2020 Revised 12 August 2021 Accepted 15 August 2021 
JIUC

16

\section{Introduction}

With the arrival of the era of the knowledge economy, intellectual property (IP) issues have become increasingly significant and the protection and management of IP have attracted universal attention. In 2008, the Chinese government launched the "National Intellectual Property Strategy," which aimed at enhancing the quality and competence of R\&D of organizations in IP creation, protection, utilization and management (The State Council of the People's Republic of China, 2008). In universities and many other affiliated institutions in China, a growing amount of research requires detailed IP creation and management plans. Therefore, professional guidance in IP analysis and management is in great demand. Moreover, in recent years scientific researchers in universities have invested more effort not only in innovation but also in expanding their R\&D mission to industrialization and commercialization, which has been reflected in a rapid increase in the number of IP applications.

To further enhance the professions of IP information services in universities, the National IP Administration and the Ministry of Education jointly issued the "Measures for the Implementation of the Construction of IP Information Service Center (IPISC) for Universities" in 2018. In 2019, the National IP Administration and the Ministry of Education jointly approved 23 national IP service centers (IPISCs) based on some three criteria: (1) possessing a mature IP information service team; (2) having domestic and foreign literature resources, databases, information analysis tools and infrastructure related to IP and (3) establishing IP management system and service work system.

All selected IPISCs are all affiliated with the university libraries, which is hoped to exert the advantages of information resources and talent resources of universities and promote collaborative innovation and transfer of technological achievements. Through online research, however, the research team found that the 23 approved IPISCs had not developed any functional systems that can provide complete IP services, while identified some issues that need to be resolved before establishing a complete service model. Based on the findings the research team explored to develop an ecological chain model that covers a complete cycle of IP service. The research team then completed the technological development of a system called Wuhan University Intellectual Property Information Service System (WHU-IPISS) to verify the model and provide IP services of the whole process for researchers in Wuhan University.

\section{Literature review}

In the United States, the US Patent and Trademark Office (USPTO) has designated numerous Patent and Trademark Resource Center (PTRC) throughout the country to assist with patent and trademark search and research (Jenda, 2005). To make full use of university resources, some of the PTRCs are directly set up within university libraries, such as Northern Kentucky University, which provides patent information services and IP awareness assessment tool. Professional staff members at PTRCs are responsible for helping researchers learn about basic knowledge of IP, assist them with IP applications and create an encouraging environment of technological innovation.

Usually, patent transfer plays an important role in IP management in universities because of the patents' market value. The United States is the first country to implement the IP strategy. At present, common IP operating strategies include the following: (1) inner administrative organization, such as Stanford University's Office of Technology Licensing (OTL) (Leute, 2005); (2) external administrative organization, such as Wisconsin University's Wisconsin Alumni Research Foundation (WARF) (Golden, 2010); and (3) outsourcing to professional organizations, such as the College Licensing Corporation (CLC) (Qiu et al., 2011). All these operating strategies have effectively improved the IP transfer rate in universities, 
increased the innovation enthusiasm of university researchers and promoted the technological innovation competitiveness of the whole country.

In universities in China nowadays, there are no specialized IP service agencies like the PTRCs or OTL in the US. Therefore, the IPISCs in the selected universities are being planned to improve the IP management mechanism of universities and realize the whole process of IP service. The strategy of establishing IPISCs in universities have attracted much attention of scholars, who have described the current situation of IP services and proposed corresponding solutions from the aspects of government policy formulation and library service reformation (Jia, 2015; Zhao, 2015; Li, 2016; Lin, 2017; Zhang et al., 2019).

Research on the status quo of IP services is the basis for the development of IP service systems, which helps identify deficiencies and propose solutions. Jia (2015) analyzed the IP services of university libraries through literature surveys and proposed that universities should continuously improve the IP service mechanism to meet the needs of users. Li (2016) focused on the investigation of patent consulting services carried out by university libraries. They introduced service models and proposed improvements to resolve the identified problems in the service process. In addition, Zhao et al. (2015), Lin (2017) and Zhang et al. (2019) utilized the methodology of interviewing and observation to investigate the IP services carried out on the websites of some university libraries in China and proposed the IP service models for different levels of demand. These researches have revealed the current situation of IP services in university libraries and pointed out some existing shortcomings in the development of IP service systems. However, the solutions proposed by this type of research lack comprehensiveness, and there is no plan formed around the entire process of IP services in universities. This research will investigate the status quo of IP services in universities and further summarize the problems to create solutions, which forms an excellent supplement to the current research on the status quo of IP in universities.

The research on the development of IP service models in universities has a positive impact on the innovation of service modes and the improvement of service efficiency. Zhang (2018) found that the IP service systems of university libraries were based on the aspects of system design and cooperation mode. Meanwhile, Ren et al. (2016) and Zhang et al. (2017) analyzed the existing problems of patent services in university libraries and proposed a docking patent service model for technological innovation. Besides, personalized patent services and new media applications have also attracted attentions of scholars. Su et al. (2016) and Zhang et al. (2018) studied the different needs and characteristics of patent services at different stages during the research process and then optimized a generic patent service model for the scientific research process in the university. Xu (2018) explored the patent information innovation service model based on the actual needs of users on self-media platforms and emphasized the advantages of using self-media platform resources for patent information services. Such research has outlined the current status and tried to resolve some existing issues in the development of IP service systems. However, this type of research focuses more on the theoretical level and does not extend the academic research to system applications. Based on forming a solution, this research further developed the prototype system, which references the practical application of current theoretical model research.

The current literature also includes some research about the future development trend of IP services in universities, which can guide the further development of IP service models in universities. For instance, Wang et al. (2015) focused on exploring the patent information service model embedded in the scientific research process and proposed the development trend of patent information services in libraries from four different aspects. What's more, Xiao (2018) discussed how the innovation service provided by libraries support curriculum and research; she then elaborated that IP services that promote the transformation of achievements become one of the top ten development trends of university libraries.
Constructing the Chinese university IPISS 
The existing research has depicted prospects for the future development of library service and guided potential inventions of innovative IP service systems. However, the practical value of such research needs to be further verified, and the combination of theoretical study and practical application needs to be further strengthened.

\section{Problem statement}

Above all, American universities have maturely practical experience in IP services and operations. PTRCs provide service guidance for university researchers in IP creation and IP operation; while organizations like Stanford University's OLT plays important roles in IP transfer. The current literature in China discusses the status quo of IP information services in universities and analyzed the shortcomings. To improve the efficiency of IP services, these studies proposed a library-based IP service model and future development system. However, it was mainly based on theoretical research with little practical development.

Theoretically, the proposed IPISCs of universities were like a combination of PTRC and OLT, extending the regular service areas by covering the whole process service of IP creation, utilization, management and protection. More importantly, a well-developed user interface or system can function as a panoramic display of the service content and service model of the IPISC, which not only improves the service efficiency of IPISC but also widely promotes the IPISC.

The research team conducted an online study on the 23 universities who are working with the National IPISC, analyzing the types of IP services, the progress of the system development, technological novelty retrieval, IP training and patent information services. During the study, the research team found that five universities did not implemented IP services in their libraries, only providing the technological information searching services; while the rest of 18 universities have relatively better implementation of IP services, among which six of them have developed IPISSs (systems for IPISCs) and provided relevant service within the library. Through the deeper investigation, however, it was found that the established IPISSs only provides information displaying, leaving much space for further improvement.

First, the IP service process of universities is incomplete, and types of services need to be enriched. At present, the IP services provided by the university mainly take patents as the core, but researchers have expressed diversified demands for IP services, resulting it many mismatches between supply and demand. Therefore, IPISC needs to include services for patent, copyright and trademark to carry out multiple types of IP services. More importantly, in 2015 the central government released a regulation to increase the minimum reward for researchers to transfer their patents, largely promoting the transfer of scientific and technological achievements and greatly arousing the enthusiasm of researchers. Their demands may involve the whole process service of technology novelty retrieval, patent application, patent portfolio, patent transfer and patent protection, which puts forward higher requirements on the service capacity of the IPISC.

Second, the efficiency of IP transfer in universities needs to be improved. According to the annual statistical report of the National IP Administration, as of December 2018 the number of invention patents issued by Chinese universities was 537,953 (National Intellectual Property Administration, RPC, 2019a, b). However, the patent transfer rate of Chinese university patentees is less than $10 \%$. As an important part of scientific research output in universities, patent occupies an important position in universities. Whether the patent can be transferred depends on the value of the patent itself and the degree of external presentation. Currently the three operation strategies and models, mentioned in the literature review, cannot effectively promote the patent transfer. Hence, how to innovate the operation mode and improve the transfer efficiency has become a key challenge for all IPISCs. 
Third, the ability of offline IP services in universities is restricted, and the service system needs to be developed. The survey results show that only six of the 23 universities (IPISCs) have developed IPISSs, which only simply display introduction while the implementation of the service mainly depends on offline processing. This operation mode leads to higher time consuming in communication when users consult the service content. Besides, it is inefficient to submit service request offline due to the lack of a submission system. Thus, when developing IPISSs, IPISCs need to focus on how to combine electronic system with IP services to realize online consultation, customized services, deposit payment, contract signing and expert services. In this way, the service efficiency and capability of IPISC can be improved.

Finally, the existing platform function needs to be improved by adopting the user-centered concept. The six developed IPISSs have only a single function of display IP information. It needs to be further equipped with online functions, involving creation, utilization, management and protection of IP products. For example, IPISSs need to be able to provide service support online, by integrating the IP expert database and the algorithm for demandexpert matching. As for the IP management and operation, besides the matching and exhibiting function modules, IPISSs need to consider building a technology demands virtual community of companies to achieve accurate patent recommendation.

The main purpose of this project is to propose a complete system, including theoretical framework and system development, to addresses the identified issues for IPISCs. Once developed, the system (IPISS) can respond to individualized, diversified and hierarchical IP service needs from the creation, utilization, protection and management of IP. More specifically, the overall procedures of IPISS development are as follows:

(1) The first step is to propose the concept of IP ecological chain and explain the four subchains of it: the application of IP supply chain, IP demand chain, IP drive chain and IP integration chain.

(2) Based on the IP ecological chain the research team develops a theoretical framework, integrated with four core functions that are designed from four aspects, reflecting the four sub-chains of the system: resource supply, demand matching, value driving and service integration.

(3) Finally, based on the complete theoretical framework, the research team starts the model implementation and develops the IPISS.

Section 4 describes in detail the theoretical framework of IP ecological chain. Section 5 demonstrates the system development to verify the applicability of the IP ecological chain model. Section 6 summarizes the work of this project and presents further optimization.

\section{Theoretical framework}

To resolve the deficiencies existing in the system development of current universities' IPISSs, the research team introduced the concept of the ecological chain in biology into the system modeling. In biology, the ecological chain contains producers, consumers and decomposers. Through the complete process of production, growth, maturity and extinction, the balanced development of the entire ecosystem is realized. In the IP service system of universities, for example, the producer is composed of IPISC and university researchers. The resources include IP information resources, IP service resources and IP transfer resources. Among them, IP information resources contain IP dynamic information, policies, service cases, etc. IP service resources provide the full range of IP services such as patent, trademark and copyright. IP transfer resources are mainly based on patents, which are uploaded by scientific researchers to seek patent transfer.

Constructing the Chinese university IPISS

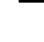


JIUC 3,1
Consumers are made up of researchers and companies who have technological needs. On the one hand, researchers are producers of resources. On the other hand, they are consumers of services, involving technical analysis, patent application, patent portfolio, patent protection and other service needs, which need the service support of IPISC. The company and the university reach the patent transfer agreement to solve the technical difficulty. In this way, the result of scientific research can be transferred into industrial value.

IPISC is also known as the decomposer, which integrates the data provided by the IP producers to build an IP resource database and captures the technical demands of companies and feeds technical demands back to researchers. Researchers will continue to produce new research outcomes to maintain the advanced nature of technology in order to force the out-ofdate technologies to disappear and to achieve the continuous updating of the entire social technology level.

Therefore, borrowing the concept of the ecological system from the discipline of biology, the research team proposed to develop a model of IP ecological chain (Figure 1), composed of

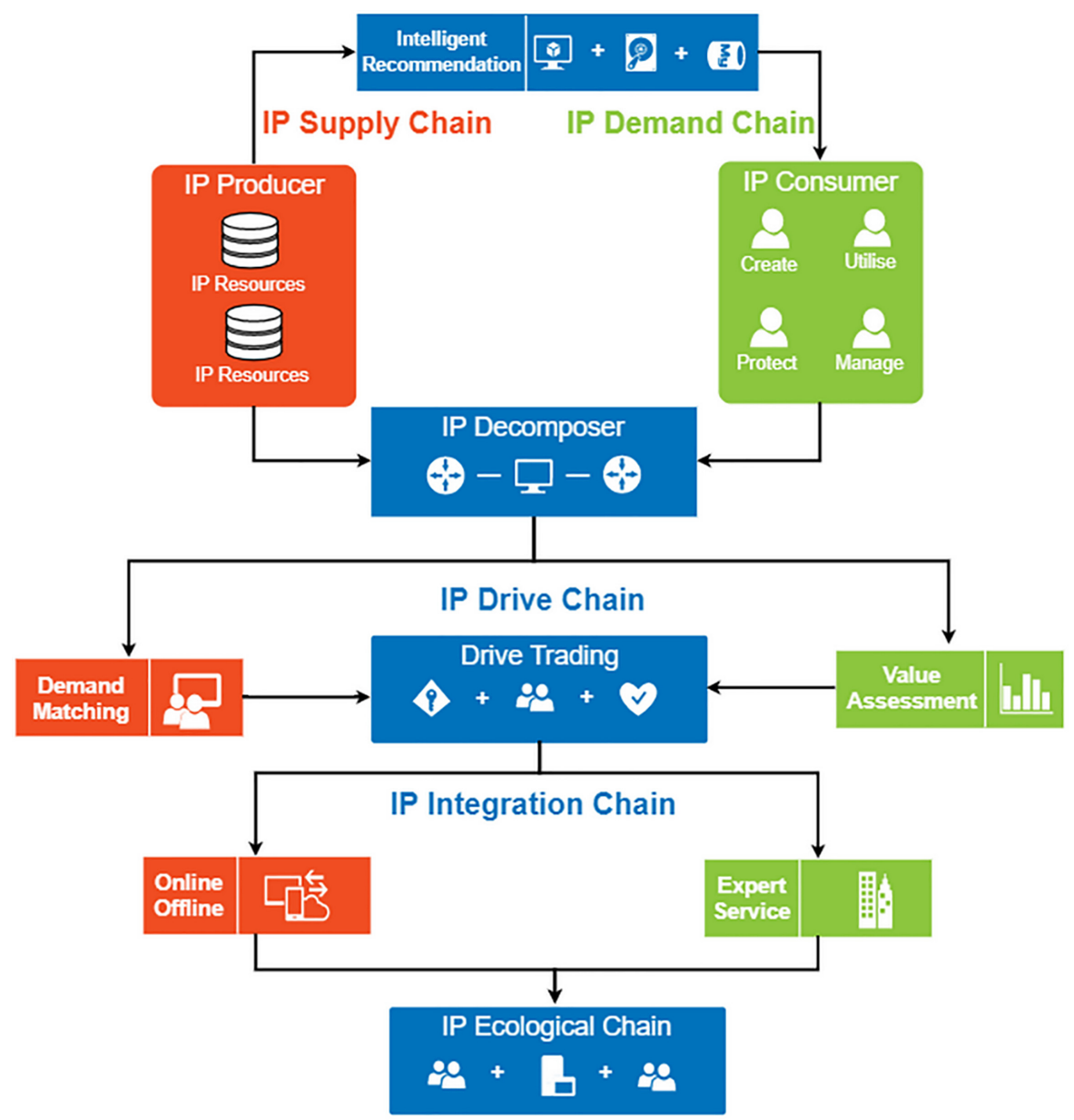

Figure 1.

IP ecological chain model 
IP producers, IP consumers and IP decomposers, covering the whole IP service process of creation, utilization, management and protection.

Figure 1 shows that the IP ecological chain covers four sub-chains, including supply chain, demand chain, drive chain and integration chain. The IP supply chain helps realize the resource gathering of IP producers, ensuring the integration of IP information resources, IP service resources and IP transfer resources. The IP demand chain focuses on the full process of IP consumers, helping achieve accurate and customized services for researchers and provide the companies with a demand expression window. Company requirements are matched by IP decomposer to push out patents that solve their technical problems. If the patent cannot be matched, it will be fed back to the IP Producer for technology research and development. The IP drive chain focuses on the economic value of IP, evaluating the commercialization value of IP producers' patents for decision making for IP consumers to improve the efficiency of patent transfer. The IP integration chain provides users with a full range of services from online to offline. With expert services as the critical support, the process of online customized service, offline completed service and online data transmission can be realized. The goal of developing such as theoretical framework is to strengthen the user-centered service concept and improve the efficiency of IP services.

\subsection{Function design of IP supply chain}

To realize the functions of data collection, effective display of IP information and resources transfer, the research team designed a multi-sourced IP resource supply system (Figure2). The IP resource supply system is composed of three sub-modules. The first module is in the personnel management system of scientific researchers, which can realize the convenient importing of patent data. The other two modules are implemented in the service management system, and IPISCs are responsible for providing IP information resources and service resources. According to the content attributes of different types of resources, classification rules are formulated. There are six categories of IP information sources, including news express, service cases, scientific

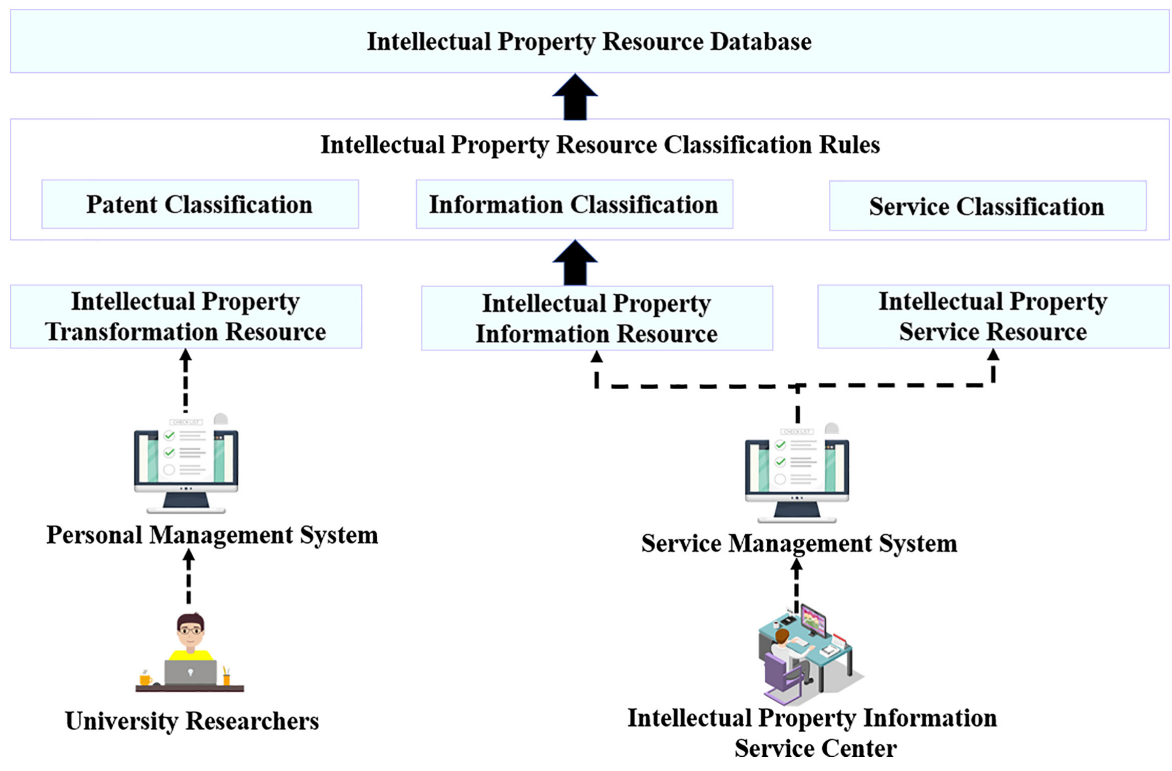

Constructing the Chinese university IPISS 
JIUC 3,1

research teams, IP encyclopedia, scientific research experts and project database. IP service resources are classified into three categories, including patent service, trademark service and copyright service, covering the whole process service types of IP. Through IP supply chain, IP producers can provide rich IP resources to the system (IP decomposer), which integrates resources uniformly to meet the diversified demands of IP consumers.

\subsection{Function design of IP demand chain}

IP demand chain focuses on the trend of individualized and diversified company technology problems. The types of services provided by IPISC cover the service needs for university researchers, so that researchers can quickly locate the services they need. However, when companies encounter technical problems, they often hope to solve problems as soon as possible so that they can maintain their technological competitiveness. Therefore, when they are trying to seek solutions, they will need to find out where to find solutions and who can solve the problem. To resolve this issue the research team designed a virtual community based on the IP demand chain, which functions as an open system for the companies to post their diversified needs and to achieve automatic identification of technology-related behaviors. Through a machine learning algorithm that is developed and implemented by the research team, the company technology requirement description and the university patent abstract will be calculated by text similarity. According to the matching value, the company was pushed to the university patent recommendation list. When the number of

- User - Insert Demand Name, Industry Category, Demand Category, Demand Description, Personal Basic Information

- User - Click "Recommended Patent"

- System - Obtain technology demands submitted by the company

Demand demand = demandService.get(id);

- System - Query the current database for patents by category

List $<$ Patent $>$ patents $=$ patentService . findAll(category);

- System - Traversing each patent in the patents collection for(Patent patent : patents) \{this.patent

- System - Use the cosine similarity to calculate the match value between the patent and demand

float matchScore $=$ public static double getSimilarity

(String demandDesc, String patentDesc)

- System - Set a match value for the patent and update the patent match value

patent.setMatchScore(matchScore); patentService.update(patent);

- System - Get paginated data, display the top ten matching patent, return to the front page and display

Page4Navigator $<$ Patent $>$ page $=$ productService. list (start, size, 2 ); return page; 
recommended solutions is fewer than five, the technical difficulty of the company will be released in the virtual community so that IP Producers who see this demand will try to invent technological solutions. The core logic code of the recommendation function of IP demand is as follows:

\subsection{Function design of IP drive chain}

The industrial and commercial value of patents determines whether patents would be transferred. The assessment of patent value has a guiding role for companies to seek patent technology. At present, the existing value assessment models include industrial law, DCF model and value increment method. However, the operation and implementation of such methods and models are not easy to achieve. The research team introduced a new evaluation model on patent values from seven aspects, including marketing application, patentee ability, patent application, patent share, market competition, policy application and patent demand.
Constructing the Chinese university IPISS

- Researcher - Insert patent name, patent type, application number, transaction price, patent description IN personal center

- Expert - Insert score in evaluation system, include:

- Market Application: Whether the patent is put into market use and the scale of application

- Patentee Ability: The ability of patentees and teams to solve problems

- Patent Application: Total patents in the corresponding field

- Patent Share: The proportion of patentee holding patents

- Market Competition: Competitors and their scale

- Policy Application: The degree of compatibility with national and local policies

- Patent Demand: Market demand for patents

- System - Calculate the patent value score

float patentValue $=$ (float $)($

patent.MarketApplication () * $0.1+$

patent.PatenteeAbility () * $0.2+$

patent.PatentApplication () * $0.15+$

patent.MarketCompetition () * $0.15+$

patent.PatentShare () * $0.15+$

patent.PatentDemand () * $0.1+$

patent.PolicyApplication () * 0.15

)

- System - Obtain current patent and set patent economic value score

patent.setPatentValue (patentValue);

patentAssessService.update(patent); 

JIUC
3,1
With the help of a comprehensive evaluation method suggested by two professors in the profession, different weights are assigned to each index, and a simple and effective weighted average method is selected to calculate the economic value of the patent. In the application process, after researcher submit patent information, experts in the relevant fields are responsible for grading each patent based on these seven aspects. The final patent score would be determined by aggregating the opinions of several experts and be displayed on the patent detail interface visually. The core logic code of patent value evaluation is as follows:

\subsection{Function design of IP integration chain}

The establishment of IPISCs in universities is a critical attempt to put the IP operation into practice. The development of IPISS is to improve the service efficiency of IPISCs. IPISCs provide various types of IP services, including patents, trademarks and copyrights, all of which need to be supported by professionals and experts. Therefore, the research team integrated the librarians, IP experts and IP service institutions into an expert database for the completion of full IP service. When any entities need to request IP services, they can select the corresponding service online, fill in the detailed requirements and deposit a service fee. After receiving customized services from researchers, IPISCs will select experts or service organizations from the expert database to assign tasks according to the type of services. When the expert completes the service, he/she can send the results to the researchers' personal center through online delivery, and the user can complete the payment of service fee after review and confirmation. What's more, when the entity who initiated the request determines to purchase the license right or patent right of a certain technology, contacts can be made with the patent inventor through IPISC and trading can be completed through IPISS. IPISC will select professional operating institutions from the expert database to carry out patent right change procedures. Through the combination of online and offline activities, the IPISCs can finally achieve a benign interaction between IP producers and IP consumers, thereby maximizes the actual service capacity for the university (see Figure 3).
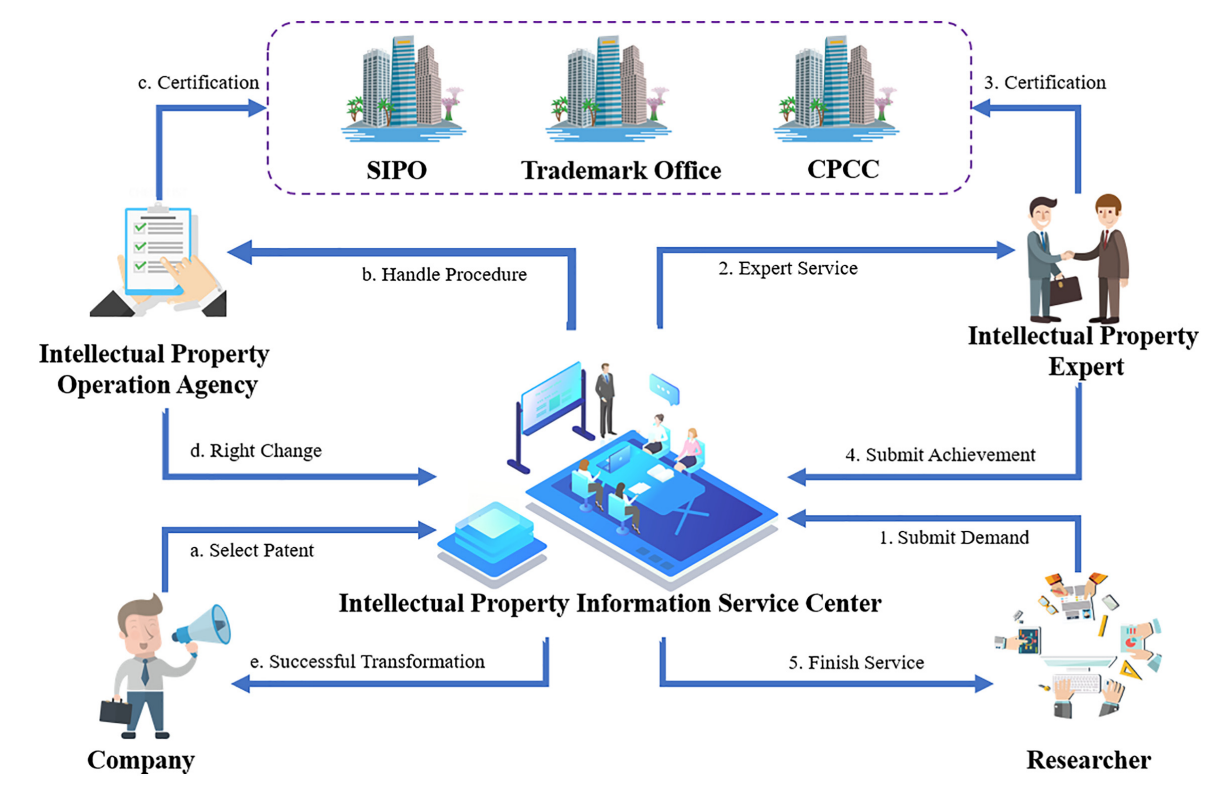

Figure 3.

Function design of IP integration chain 


\section{System development}

Under the guidance of the proposed theoretical framework (IP ecological chain model) and the function designs of the four sub-chains, the research team then developed a system IPISS prototype (Figure 4) and completed the final system implementation to Wuhan University.

The main content and application technologies integrated with the IPISS development include the following five essential parts:

(1) Front-end interface layer: IPISS front-end interface layer includes user interfaces, personal center and IP management center. The IP management center contains IP information display, researchers' scientific and technological achievements display, IP service display, IP expert consultation and a series of the data management modules. The front-end interface was mainly implemented by progressive framework Vue.js., and the visualization of patent value was realized by open-source tool ECharts. To reduce the coupling between front-end display and back-end server, AJAX asynchronous request and JSON were used to realize data exchange between front-end and back-end.

(2) Business process layer: The business process layer is the key module of the whole system, which corresponds to different roles and generates business outputs. Researchers who desire to transform scientific and technological inventions can follow the procedure to upload patent information on this layer. Users can also seek information consultation, request service customization and conduct order management on this platform. For those experts who are providing services, they can perform patent evaluation and provide complete IP service to the requesters.
Constructing the Chinese university IPISS

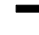


JIUC

Moreover, those companies in need of technology commercialization can use the platform to disclose their technical difficulties and search for the accurate patent recommendation. In the technological domain, the implementation of the whole business process layer is based on Spring Boot framework, and the Spring MVC and RESTful technology are used to realize the open interface. The data access layer is based on MyBatis as ORM framework, which can better meet the data access requirements of the system.

(3) Data storage layer: On the IPISS, researchers, industrial enterprises and IP service experts will produce a large volume of data on the platform. To achieve effective data management and real-time response to page content, the data storage layer of the system consists of two parts: data caching layer and data persistence layer. MySQL was used to implement the data persistence layer, and Redis was implemented to cache data in the data caching layer.

(4) External interface layer: Since the IPISS involves various types of users and resources, many storage fields will be needed in the process of storing, cleaning and integrating, which lead to the need of large data capacity. At the same time, in order to improve efficiency, external data interfaces need to support online importing of data in various formats, such as.txt,.xlsx and.csv. This requires the system to have, according to the unified IP resource metadata framework, the functions to automatically clean, integrate and store data. Therefore, the research team formulated a unified metadata framework of IP resources based on some practical experience in the field of information organization and database services. Through this layer, the research team provides an easy-touse data importing interface to the users, realizing the effective aggregation of IP resources.

(5) Data analysis layer: Many complex algorithm models were built in the system development, which provided decision-making support for IP producers and IP consumers. The used algorithms include the user demand analysis model, patent evaluation model, user data collection model and resource intelligent recommendation model. Considering the increasing trend of data, the research team developed a big data analysis framework based on Hadoop, realizing the distributed storage of massive data by HDFS and achieving the distributed data calculation by MapReduce. The layer was then designed to complete the data transmission between MySQL and HDFS by Sqoop and programed to perform the data statistical analysis by Hive and R. Finally, based on the analysis results the IPISS can generate operation analytic reports, IP transaction analytic reports and user behavior analytic reports.

\subsection{Front-end user interface of IP resource supply management}

The front-end interface of IP resource supply is the reflection of the IP supply chain, where news releases, IP information and policies are automatically collected and uploaded from the information resource supply module and displayed on the homepage to provide users with real-time IP information (see Figure 5). According to the types of IP services that have been carried out in universities and combined with research on the IP service needs of researchers, 150 IP services are fed to the IP service interface (see Figure 6). A classification system of IP transfer resources is also provided based on the standard classification of industries. Researchers can upload patent information through the personal management center and display it on the IP trading interface (see Figure 7). 

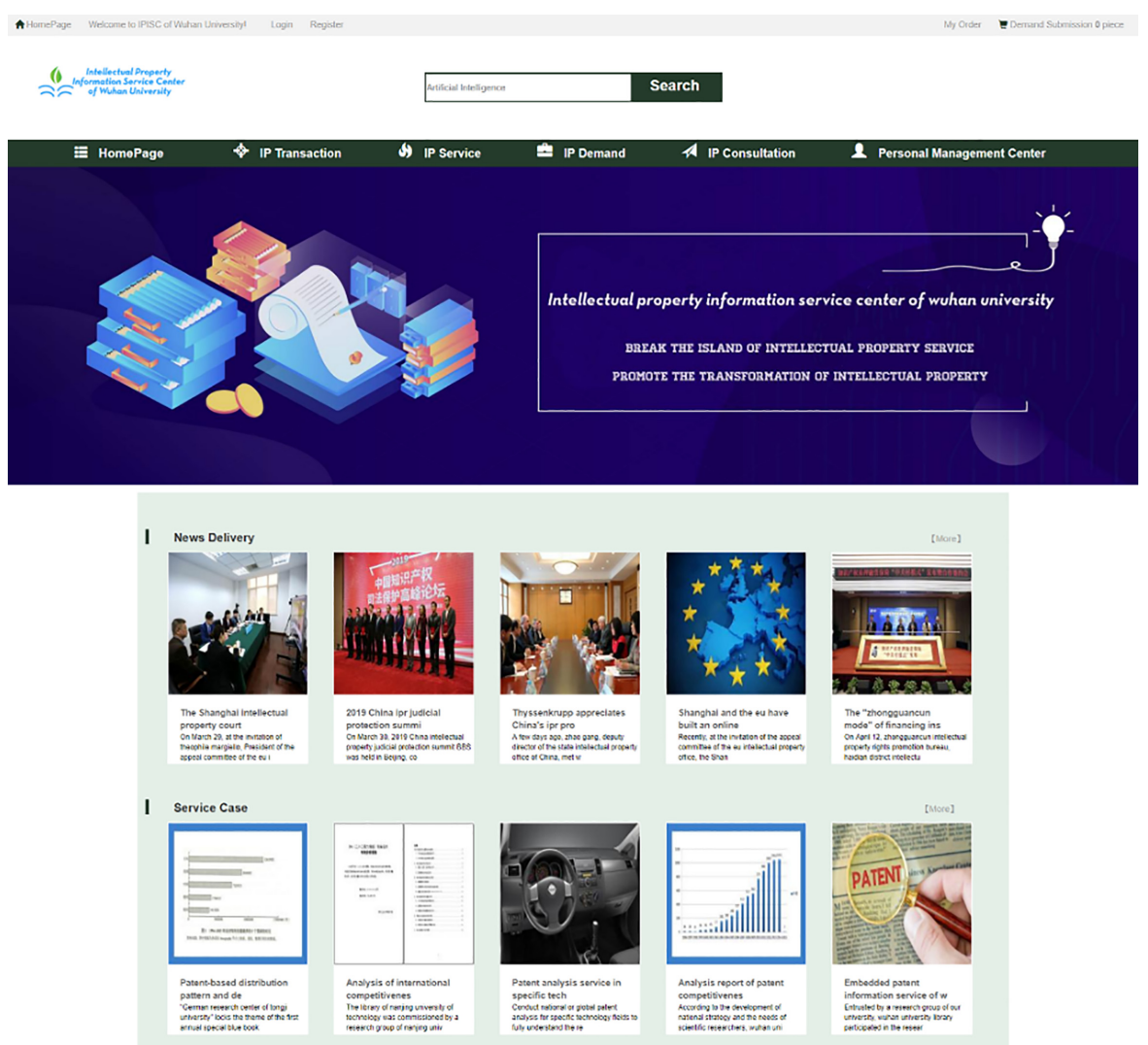

Constructing the Chinese university IPISS

\subsection{User interface of IP demand matching}

The user interface of IP demand matching is the realization of the IP demand chain. When the service requestor submitted its IP service needs to IPISS (see Figure 8), the system would quickly screen the patent data under the corresponding classification in the IP transfer resource database. According to the submitted demand description and patent abstract, the matching algorithm would be automatically triggered to function, and the top twenty patent information threads would be selected to form a patent list and fed to the submitter (see Figure 9). The IP requestors can view the basic patent attributes, patent specifications and claims based on the results and then accurately identify the specific patent that meets the requirements.

Based on system recommendation, requestors can also explore research teams and discover potential opportunities for cooperation. When the recommended patent list is fewer than five, the system would feed the requests into the virtual community (Figure 10). By doing this, the researchers in the community were able to stay updated with the technical difficulties on the current market and try to invent solutions. Through this designed mechanism, both parties of IP service can get involved for meaningful interactions and making the transfer of research outcomes. The developed function contributes to solution on technical issues in industrials and the deepening of academia-industrial cooperation. 


\section{JIUC 3,1}

\section{8}

Figure 6.

Display interface of IP trading information
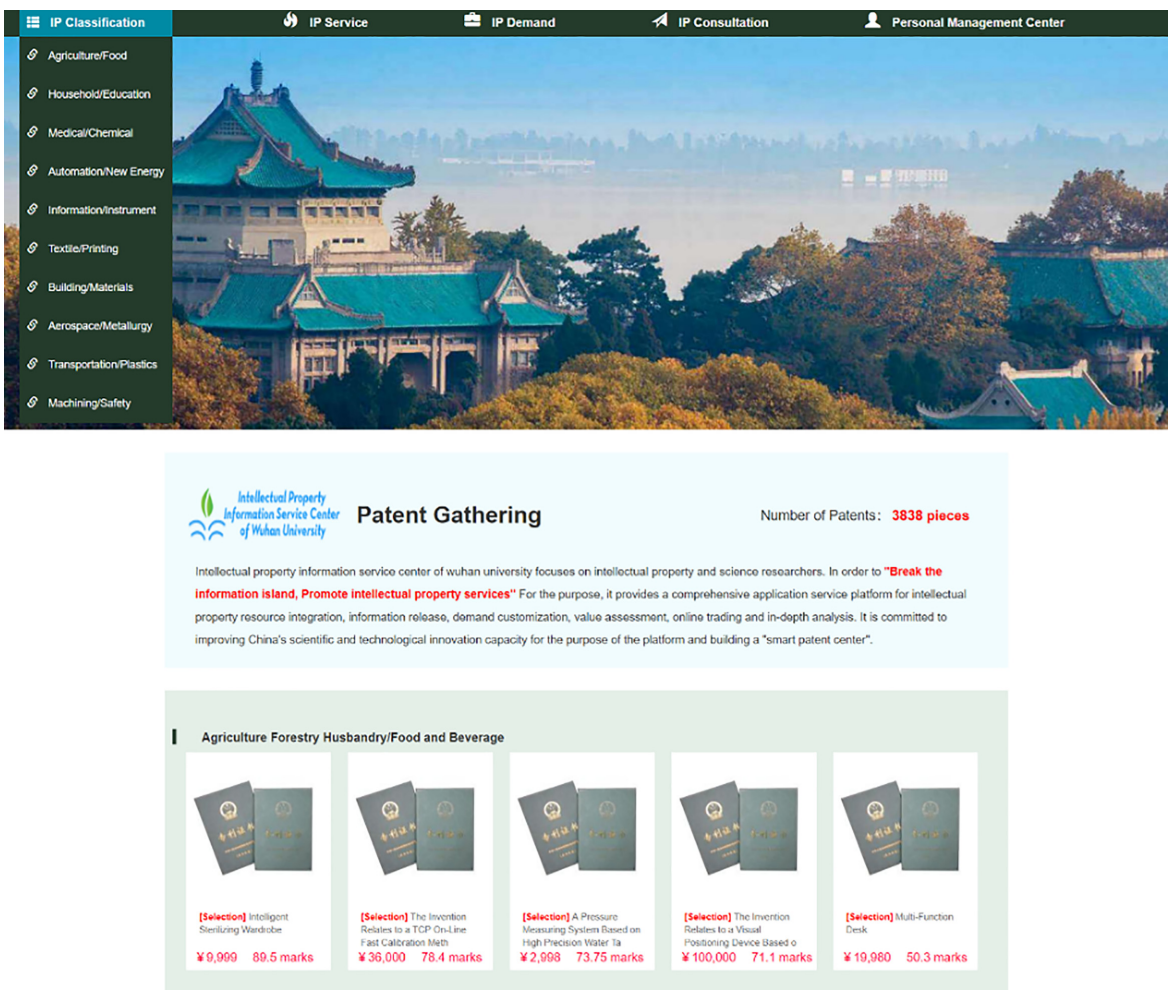

\subsection{User interface of IP assessment system}

The front-end interface of IP assessment is the realization of IP drive chain, assessing the value of patents. After the researchers' submitting the patents to IPISS, the professionals in the corresponding fields would grade the patents using the evaluation indicators. The system automatically calculates the patent score according to the formula and displays it on the patent detail interface with a transfer report (Figure 11). The patent reports provide decision-making supports for the requestors in finding research teams and seeking patent transfer.

\subsection{User interface of online-offline expert support system}

The user interface of online-offline expert support system is the reflection of the IP integration chain. Because of different types of IP services catering to different needs such as patent transfer process, it is necessary to involve IP experts to provide service support to avoid property disputes, transaction delays and other problems that cannot be predicted. The implemented WHU-IPISS integrates librarians, professors from universities and lawyers from IP service institutions to build an IP expert database, aiming to provide professional coverage on the whole process of IP services.

The system provides an expert consultation window (Figure 12), providing professional one-on-one consultation on to the users. On the interface users can choose experts in different professions to raise questions and start the consultation. Users can also directly submit their requirements online, where service providers can receive the request and carry out the task 


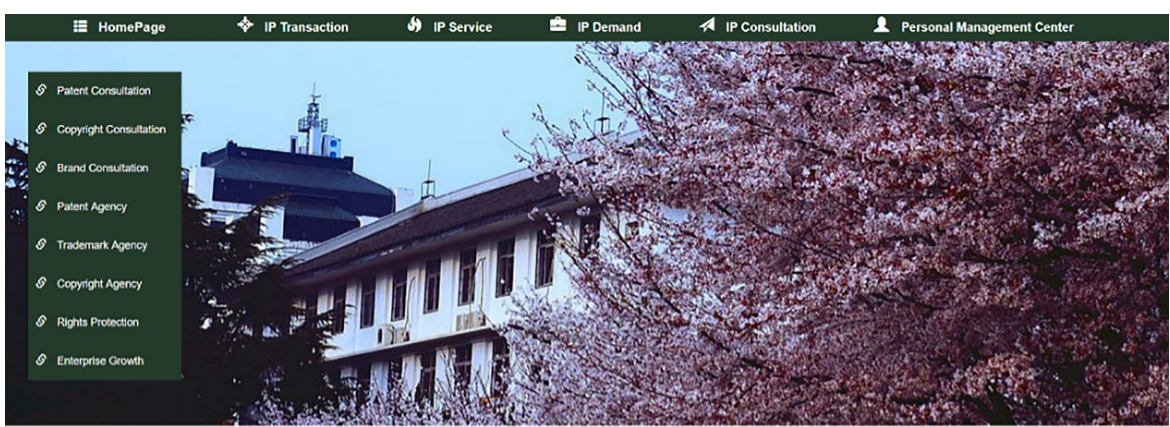

Constructing the Chinese university IPISS

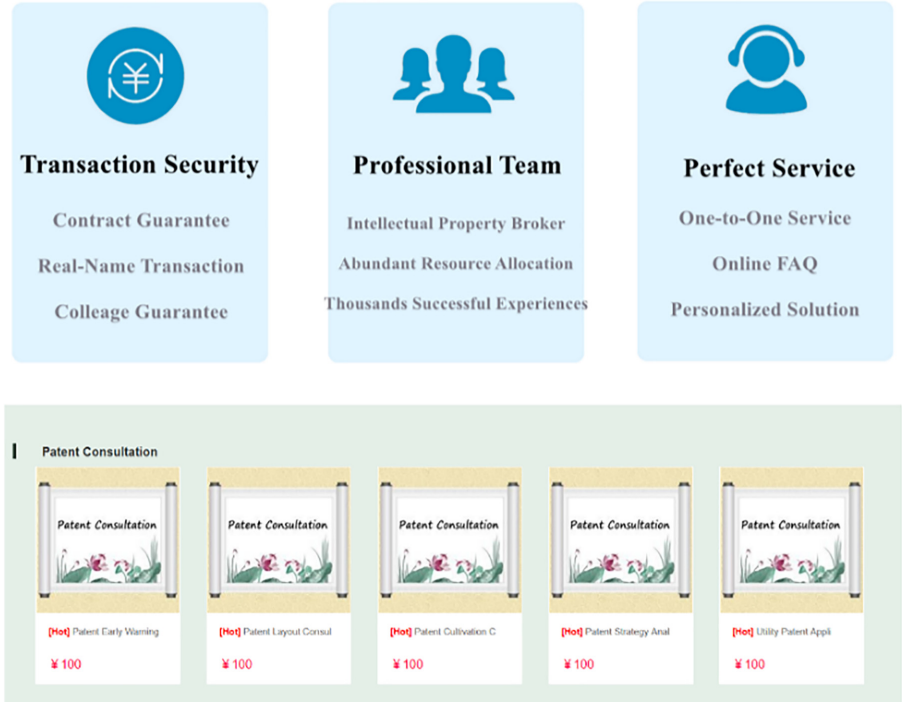

Figure 7.

Display interface of IP service

offline, such as analysis report writing, IP application and IP litigation. For example, in the process of seeking a patent transfer, IP experts can coordinate the requestors and the patent holders to negotiate offline; and after reaching an agreement the patent trading can be completed through the system. Relying on the support of the IP expert database, WHU-IPISC has extended the IP services, so that users only need to complete their request submission and the WHU-IPISS will entrust experts to complete the services offline, effectively improving the service efficiency of IPISC and providing a full process solution for the IP needs.

\section{Conclusion}

Supported by the domestic innovation-driven development strategy and the goals of developing a healthy industrial environment for intellectual properties, China has achieved some developments in IP protection and services. Higher education institutions such as universities, especially university libraries are in an advantageous position of collecting 


\section{JIUC 3,1}

30

Figure 8.

Submission page of technology demand

Figure 9.

Display interface of patent matching list

Figure 10.

Virtual community of user demand

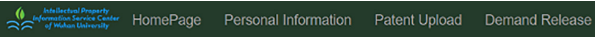

Denradracese

\begin{tabular}{|c|c|c|c|c|c|c|c|c|c|}
\hline Demand Name & Industry Categories & Demand Type & Contact & Phone & E-mail & Address & Demand Detail & Match Patent & Delete \\
\hline $\begin{array}{l}\text { Need sterilizing } \\
\text { wartrobe fecthnical }\end{array}$ & Green Energy & Technical Problem & Mr. He & 17887879696 & $676543243 @ 9 q .00 \mathrm{~m}$ & $\begin{array}{l}\text { Wuhan, Hubei } \\
\text { province }\end{array}$ & $\begin{array}{l}\text { Urgently needs a wellvenentiated sterilized warcrobe. The } \\
\text { requirements are a mature lectnology, low price, and high efficiency. }\end{array}$ & [7] & 调 \\
\hline
\end{tabular}

\begin{tabular}{|c|c|c|}
\hline \\
\hline \multicolumn{3}{|c|}{ pload Demand Relea } \\
\hline 976 & A Well-Ventlataded Sternized Warcrobe & $65.47 \%$ \\
\hline 968 & Intelligent Sterillzing Wardrose & $65.47 \%$ \\
\hline 972 & The Inventon Relates to a Visual Postitoning Device Based on Arroncla Intelllyence & $13.25 \%$ \\
\hline 970 & A Pressure Measuring System Based on Hign Predision Water Tank & $4.88 \%$ \\
\hline 975 & The Utilly Model Relates to a Pipeline Cleaning Devilce & $0 \%$ \\
\hline
\end{tabular}

The Utilly Model Reates to a Pipeline cle

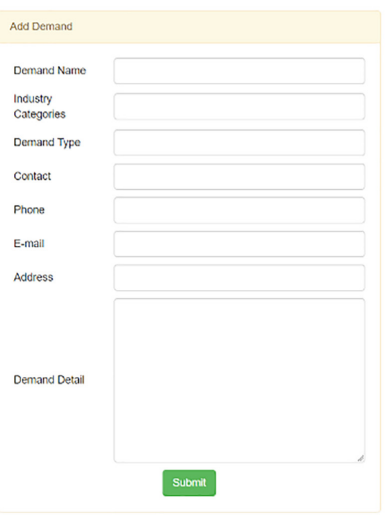

E HomePage $\quad$ IP Transaction $\quad$ S IP Service $\quad$ IP Demand $A$ IP Consultation $\Omega$ Personal Management Center

\section{Technical Problem Unmet Demand}

Research on Welding Technology of Electric Track Connecting Wire

Aindustry: Mechanized Equipment OCreate Date: 2019-07-24

2Contact: Ms. Huang Changsha,Hunan Province

ADemand:

9715000 As the subway track is used as the backllow conduction of power supply for trains, a large number of connection cables need to be welded on the tracks at both ends of the joints to ensure the passage of current, so it is necessary to study the welding technology of the electric connection lines to ensure the reliability of the electric connection and avoid or reduce the damage to the rail.

\section{Undertake}

Demand

information resources and gathering professional personnel resources. The domestic market, including the academia and industrials, are in urgent needs of and strongly encourage the development of IP service center and systems. Such systems, once developed, would play a 


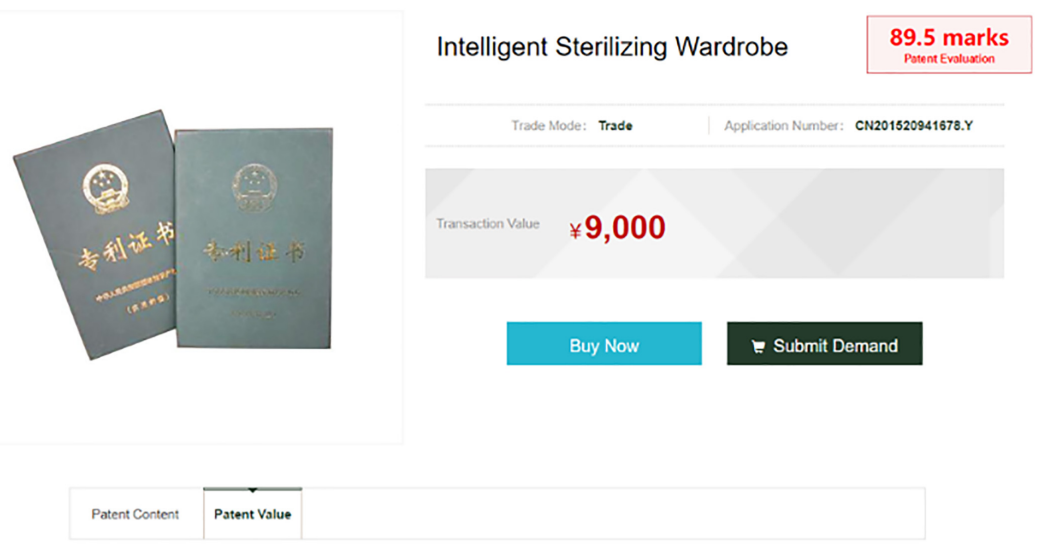

Constructing the Chinese university IPISS

Economic Value: 89.5 marks

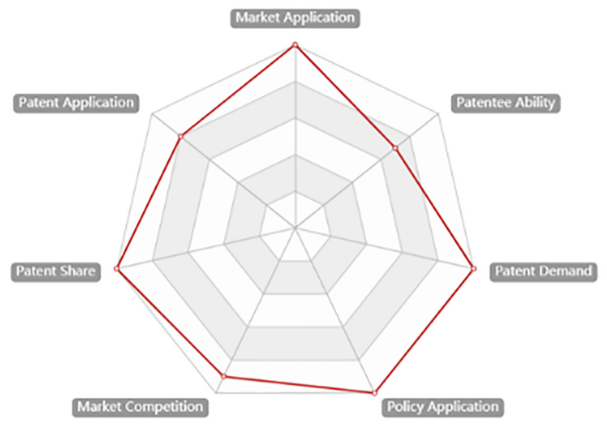

Conclusion of IP Information Service Center of Whu:

Whu IP Information Service Center integrates expert opinions. From the perspective of patentometrics analysis 《Intelligent Sterilizing Wardrobe》. The development of the technology,technical characteristics and the current development trend of the field was mined by experts.Experts evaluate the economic value degree of this patent and calculate the economic value degree score of this patent as 89.5 marks. It reflects that this patent has high value and is suitable for Industrial application.

Figure 11.

Display interface of patent value assessment

vital role in continuously improving the public service system of IP and promoting scientific and technological innovation.

This research team conducted studies on the university IPISCs from the aspects of practical services, development models and implemented systems and identified many issues, conceptual and technical, that need to be resolved. Based on the study result the research team proposed a theoretical framework called IP ecological chain and perform function design for the four sub-chains in the eco-system. Under the guidance of the theoretical framework, the IPISS was then developed and implemented. The system realizes 


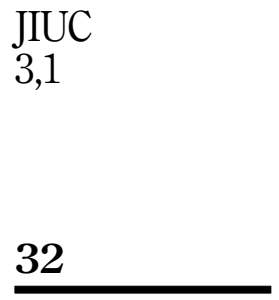

Figure 12. Interface of expert support system

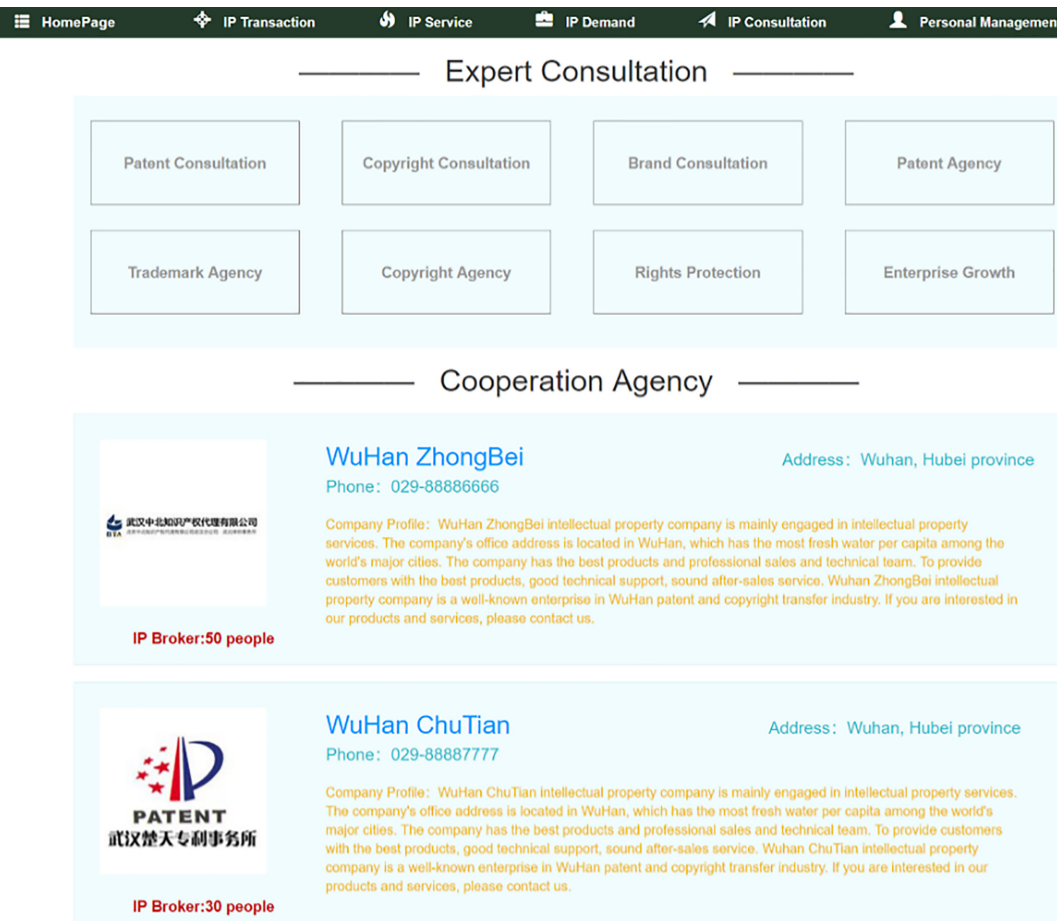

the one-stop comprehensive service function from IP resource integration, IP information release, IP demand customization, IP transfer, IP evaluation, IP recommendation and IP trading. It solves the predicament of IP services among all stakeholders. Currently, the completed WHU-IPISS is functioning properly and is expected to exemplify system developments for other universities.

To test whether the system's operating model can be applied in other universities, the research team will release the algorithm, the system's original codes and complete documentation for reference to other universities. At the same time, the research team will actively seek cooperation with other universities' IPISCs and their development groups to continuously improve the functions of the current system and hope to contribute more to the field of both IP discipline and system development. There are also some problems in the current system, which will be continuously optimized in the future. On the one hand, the patent recommendation function needs to be further optimized. The recommendation process of the current system is "passive" recommendation, which only achieves the matching of enterprise demands and needs to be further strengthened in terms of the realtime and accuracy of recommendation. In the future, enterprise portraits and multiple types of recommendation methods will be integrated into the system. On the other hand, the patent value evaluation function needs to be further upgraded. At present, the patent value evaluation function of the system is too dependent on expert scoring, and the evaluation efficiency is low. In the future, machine learning will be used to realize the automatic evaluation of patent value. Furthermore, the patent market price estimation function will be added to the system to achieve a panoramic display of patent value. 


\section{References}

Golden, J.M. (2010), "WARF's stem cell patents and tensions between public and private sector approaches to research", Journal of Law Medicine and Ethics, Vol. 38 No. 2, p. 314.

Jenda, C.A. (2005), "Patent and trademark depository libraries and the United States Patent and Trademark Office: a model for information dissemination", Resource Sharing and Information Networks, Vol. 18 Nos 1-2, pp. 183-201.

Jia, C.J. (2015), "On the present situation and improvement of public service supply of intellectual property in China", Scientific Management Research, Vol. 33 No. 2, pp. 5-8.

Constructing the Chinese university IPISS

Leute, K. (2005), "Patenting and licensing of university-based genetic inventions - a view frorn experience at Stanford University's Office of Technology Licensing", Community Genetics, Vol. 8 No. 4, pp. 217-222.

Li, F. (2016), "Research on the exploration and practice of patent information service in university library", Library Development, Vol. 2016 No. 7, pp. 78-81.

Lin, Q. (2017), "Library intellectual property service for hierarchical needs. Library and information service", Library and Information Service, Vol. 61 No. 1, pp. 67-69.

National Intellectual Property Administration, RPC (2019a), 2018 China Patent Investigation Report, National Intellectual Property Administration, RPC, available at: http:/www.cnipa.gov.cn/docs/ 20190819144147879142.pdf.

National Intellectual Property Administration, RPC (2019b), Domestic Patents in Force According to Service, National Intellectual Property Administration, RPC, available at: http://www.cnipa.gov. cn/tjxx/jianbao/year2018/c/c4.html.

Ren, J.X., Zhao, N. and Ji, Y. (2016), "Research on patent service mode of university library under the environment of innovation and entrepreneurship", Journal of Modern Information, Vol. 36 No. 8, pp. 27-31.

Su, Q.X. and Yang, Z.K. (2016), "Research on patent service of university library facing scientific research process under big data environment", Library Work and Study, Vol. 2016 No. 20, pp. 81-86.

The State Council of the People's Republic of China (2008), Outline of the National Intellectual Property Strategy, The State Council of the People's Republic of China, Beijing.

Wang, L.P., Yang, B., Qin, X. and Tu, Y.Z. (2015), “The content, mode and trend of patent information service in university library", Library and Information Service, Vol. 59 No. 6, pp. 113-119.

Xiao, L. (2018), "Research on the service innovation trend of university library supporting the construction of 'double first-rate' construction", Journal of Academic Libraries, Vol. 36 No. 5, pp. 43-51.

$\mathrm{Xu}, \mathrm{S} . X$. (2018), "Discussion on the patent information service mode of university library from the perspective of 'double first-rate", New Century Library, Vol. 2018 No. 9, pp. 24-27.

Zhang, C. (2018), "Research on the cooperation mode of intellectual property information service in university libraries", Research on Library Science, Vol. 2018 No. 20, pp. 78-80.

Zhang, Y. and Zhao, Q.L. (2018), "Analysis and design of intellectual property one-stop intelligent service platform”, Computer Knowledge and Technology, Vol. 14 No. 15, pp. 111-112.

Zhang, L.G. and Xu, Z.Y. (2019), "Analysis on the intellectual property information service of university library under the background of 'double first-rate' construction”, Library Work and Study, Vol. 2019 No. 6, pp. 115-119.

Zhang, S.J., Chen, W.J. and Lu, Y.K. (2017), "The strategy of patent information service of university library under the demand of industrial technology innovation", Library and Information Service, Vol. 61 No. 21, pp. 64-70.

Zhao, H. and Wang, L. (2015), "Research on patent information service of university library", Library Work and Study, Vol. 2015 No. 6, pp. 86-88. 
JIUC 3,1

34
About the authors

Prof. Congjing Ran, Ph.D., is an advisor of the doctoral students, School of Information Management, Wuhan University. His research interests include intellectual property management, patent analysis, data sovereignty, big data governance and open government data.

Kai Song, is a doctoral student, School of Information Management, Wuhan University. Kai Song is the corresponding author and can be contacted at: songkai@whu.edu.cn

Le Yang is a doctoral student, School of Information Management, Wuhan University.

For instructions on how to order reprints of this article, please visit our website: www.emeraldgrouppublishing.com/licensing/reprints.htm Or contact us for further details: permissions@emeraldinsight.com 